\title{
The Challenges of Low Voltage Distribution System State Estimation-An Application Oriented Review
}

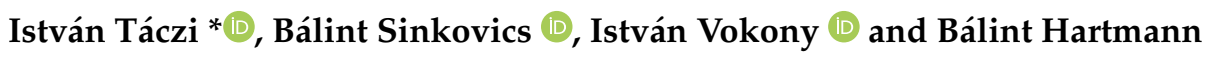 \\ MTA-BME Lendület FASTER Research Group, Department of Electric Power Engineering, Budapest University \\ of Technology and Economics, 1111 Budapest, Hungary; sinkovics.balint@edu.bme.hu (B.S.); \\ vokony.istvan@vik.bme.hu (I.V.); hartmann.balint@vik.bme.hu (B.H.) \\ * Correspondence: taczi.istvan@edu.bme.hu
}

check for

updates

Citation: Táczi, I.; Sinkovics, B.; Vokony, I.; Hartmann, B. The Challenges of Low Voltage Distribution System State Estimation-An Application Oriented Review. Energies 2021, 14 , 5363. https://doi.org/10.3390/ en14175363

Academic Editor: Antonio T. Alexandridis

Received: 7 July 2021

Accepted: 19 August 2021

Published: 28 August 2021

Publisher's Note: MDPI stays neutral with regard to jurisdictional claims in published maps and institutional affiliations.

Copyright: (C) 2021 by the authors Licensee MDPI, Basel, Switzerland. This article is an open access article distributed under the terms and conditions of the Creative Commons Attribution (CC BY) license (https:/ / creativecommons.org/licenses/by/ $4.0 /)$.

\begin{abstract}
Global trends such as the growing share of renewable energy sources in the generation mix, electrification, e-mobility, and the increasing number of prosumers reshape the electricity value chain, and distribution systems are necessarily affected. These systems were planned, developed, and operated as a passive structure for decades with low level of observability. Due to the increasing number of system states, real time operation planning and flexibility services are the key in transition to an active grid management. In this pathway, distribution system state estimation (DSSE) has a great potential, but the real demonstration of this technique is in an early stage, especially on low-voltage level. This paper focuses on the gap between theory and practice and summarizes the limits of low-voltage DSSE implementation. The literature and the main findings follow the general structure of a state estimation process (meter placement, bad data detection, observability, etc.) giving a more essential and traceable overview structure. Moreover, the paper provides a comprehensive mapping of the possible use-cases state estimation and evaluates 27 different experimental sites to conclude on the practical applicability aspects.
\end{abstract}

Keywords: low voltage state estimation; distribution system state estimation; active distribution systems; low voltage grid control; observability; meter placement; pseudo data generation; grid models; pilot projects

\section{Introduction}

Since its first proposal by Schweppe in 1969, state estimation (SE) has become a central element of power system operation, especially in high voltage (HV) transmission networks. The challenges transforming power systems (electrification, smart grids, variable renewable energy sources, distributed generation, etc.) have brought the need for SE to the forefront of distribution network operation and planning as well. This has led to increased research activities culminating in hundreds of papers published in this field. High quality reviews of distribution system state estimation (DSSE) in general have been presented in a number of papers lately. Primadianto introduces a summary of state-of-the-art DSSE techniques, grouping scientific papers based on the type of algorithm they use [1]. A similar scientific scope was defined by Majdoub et al. in [2], with the aim of highlighting the spread of techniques that are based on evolutionary algorithms.

Dehghanpour et al. created a detailed comparison from the perspectives of mathematical problem formulation, application of pseudo-measurements, metering instrument placement, network topology issues, impacts of renewable penetration, and cybersecurity [3]. On the contrary, the potential value of DSSE in enabling smart grid features was focused by Ahmad et al. comparing main differences of transmission and distribution network applications of SE [4].

The present paper is intended to take a different approach on the subject and present recent advances in the perspective of practical applications of low voltage (LV) DSSE. LV distribution networks exhibit important differences compared to medium voltage (MV), 
e.g., the presence of phase-unbalanced loads and subsystems that do not use all phases, the presence of the neutral conductor, and a different approach to topology processing.

The authors have performed an extensive literature review, which covers the timespan from 2016 to 2021 with a scope to emphasize the state-of-the-art LV DSSE solutions from around the world and provides an outlook to MV DSSE. The differences and unique barriers of MV/LV DSSE implementation are discussed in each section separately. While state estimation has been in daily use for decades in transmission system operation and control, different concepts have to be applied to LV networks because of the lack of measurements and other necessary information sources. There are several modern challenges at distribution level (smart grids, smart metering, high penetration of intermittent distributed generation, and dynamics of microgrids), which will benefit from well-performing LV DSSE, therefore the scope of the analysis was two-fold:

- Identify the constraints in each stage of the DSSE process which are applicable to a LV area;

- Create an assembly of practical applications, pilot projects, and experiences.

The paper was organized around the process of DSSE, as the important differences were collected regarding topology checks, grid structural constraints, meter placement and observability, algorithm specialties, and error calculation. The main contribution of this paper is a practical application-oriented review, which compares the novel theoretical methods while considering the limitations from actual grids. The assumptions are confirmed with a detailed analysis of pilot projects; therefore, the crucial challenges, as well as the state-of-the-art methods, are identified with an implementation focus.

The paper is organized as follows. An extensive DSSE application landscape and the set of possible application fields are introduced in Section 2. In addition, Section 3 contains an application-oriented review of DSSE systems and highlights the most important constraining factors, such as observability, meter placement, and algorithm optimization methods. Beyond the theoretical aspects, Section 3 introduces the main results of demonstrations and pilot projects, offering a comprehensive overview of the state-of-the-art solutions. Finally, Section 5 summarizes the main conclusions of the review and designates the path of development for a LV DSSE system.

\section{Literature Review of DSSE Use-Cases}

SE solutions are well known in industrial and academic areas. In the last couple of decades, the transmission system operators' (TSO) daily operation was based on SE calculation and estimation to formulate an optimal operation and to be prepared for the necessary control actions. The novelty of the approach described later is that the experience and knowledge, which was worked out in the TSO area in the last $30-40$ years, plans to move into a new area: to the distribution level, focusing on medium and low voltage level adaptation.

Generally, at the LV level, outage management and control possibilities are usually not available, or cover a small part of the technical needs. The reason is simple: the investment needs of the assets and devices are high enough that there is no return at all. To give further support for distributed operation and control and to demonstrate how to utilize the available information in different heterogenous subsystems, E.ON Distribution system operator (DSO) Hungary decided to develop a unique LV supervisory control and data acquisition (SCADA) system focusing on workforce management functionality. There are several IT systems that can give useful information about the LV network, such as the geographical information system (GIS) or the SAP data management system. If these information types are connected, the data can be monitored on the same platform, and the possibility is given to perform data analysis and prediction, resulting in a more integrated DSO operation than before.

To extend the current functionality of LV SCADA, the focus of this chapter is to investigate the available applications in this area, to analyze the state-of-the-art DSSE solutions, and to select the most valuable use cases to offer effective modules to live 
operating application. This indicates that the DSSE functionality provides new possible business use-cases on the advanced distribution management system (ADMS) platform. In that perspective, the ADMS will be extended with DSSE based new functionalities. In the following, a collection will be introduced about those business use cases, and in the next chapter, the possible enhancement suggestions will be described in consideration of DSSE algorithms and measurements themselves. Although actual pilot projects with on-site results of an operating DSSE and experiences are overviewed in Section 4, the use cases from those projects are all covered by the research examined here. In several studies, a dozen of use cases are introduced [5], such as load and generation profile creation, distributed energy resource management, active network element (on-load tap changing transformer, demand side management, and energy storage), topology analysis (feeder and phase detection) technical loss monitoring, or non-technical loss identification (illegal direct connections and tampered meters) [6]. One of the most common applications is short-circuit power estimation [7]. Another specific application is outage management [8]. The classical meaning of "generation and demand forecast" is expanding in the smart grid terminology with renewable generation estimation. To avoid the immediate investment needs, the planned connection allocation of renewable generation is a possible answer, e.g., Sampaio proposes [9].

A commonly appearing DSSE application is the fault localization on LV and MV grids. Jamali and Bahmanyar proposed an approach based on sparse measurement that enhances the localization method [10]. Several applications can be further developed, such as Jamali et al. using smart metering as a data source [11]. Liu and He utilized the most commonly used weighted last square (WLS) approach [12]. Furthermore, advanced information technology offers additional opportunities [13], as well as innovative architectures [14,15]. The current level of observability (lack of measurement devices and expert systems) makes effective fault localization difficult. Therefore, considerable human resource is used at the moment, which can be replaced by advanced DSSE. The most crucial performance index at the LV level is service availability, and the next is the quality of service. Consequently, power quality estimation is another important use case, as it is demonstrated in [15] by Yu and Cobben. One of the least common applications is about losses and harmonics, such as Melo et al. describes [16]. Voltage quality issues, e.g., sag and dip volume estimation, are also feasible [17].

Unique solutions include the e-mobility-specific or the LV observability enhancement solutions, which provide promising results if the circumstances are appropriate [18]. Table 1 summarizes the technical applications of DSSE in four main categories based on the literature review. Focusing on the LV level, the identified applications are not relevant (marked with italic): fault localization is not important due to the size of one MV/LV transformer area (the selective protection scheme accurately highlights the fault location), while short-circuit power estimation does not carry any useful information for operators at this level. Feeders are usually also trivial due to the radial structure and low level of automation. The group (third column of Table 1) of renewable and e-mobility integration highly depends on regulatory models (e.g., support schemes such as net metering excludes the controllability of renewables), existing market condition (no service is available for charging control), and technical limitations (communication devices are not available for remote control, or smart asset is not available). These groups are only relevant at exact locations, but the number of such $\mathrm{LV}$ areas are increasing as active distribution systems are developing.

Summarizing the DSSE application landscape, the key is considering the economic aspects, besides the tempting technical possibilities, due to the high investment costs of DSSE hardware. Collecting the value propositions is important in the conceptualization phase. The literature review showed that most of the DSSE-related functions are software developments; therefore, a prioritization is needed that considers the local parameters (incl. instrumentation specification of DSSE). This can help to identify the true values for LV SCADA expansion at the E.ON DSO Hungary. 
Table 1. Classification of possible DSSE utilization based on the literature review.

\begin{tabular}{cccc}
\hline $\begin{array}{c}\text { Outage Management } \\
\text { and Power Quality }\end{array}$ & Data Analysis & $\begin{array}{c}\text { Renewable and } \\
\text { E-Mobility Integration }\end{array}$ & Coordinated Control \\
\hline $\begin{array}{c}\text { Human workforce } \\
\text { management }\end{array}$ & Profile creation & Curtailment & $\begin{array}{c}\text { Power electronic } \\
\text { controllers } \\
\text { (distribution level) }\end{array}$ \\
\hline $\begin{array}{c}\text { Outage information } \\
\text { handling (single \& } \\
\text { group faults) }\end{array}$ & Feeder detection & P-Q control setpoint & $\begin{array}{c}\text { On-load tap changing } \\
\text { distribution } \\
\text { transformers }\end{array}$ \\
\hline $\begin{array}{c}\text { Fault localization, short } \\
\text { circuit power estimation }\end{array}$ & Phase detection & Pattern analysis & Energy storage \\
\hline $\begin{array}{c}\text { Voltage limit } \\
\text { violations }\end{array}$ & Loss monitoring & Accurate estimation & $\begin{array}{c}\text { Demand side } \\
\text { management }\end{array}$ \\
\hline Asymmetry & $\begin{array}{c}\text { Non-technical loss } \\
\text { identification }\end{array}$ & $\begin{array}{c}\text { Hosting capacity } \\
\text { calculation }\end{array}$ & Voltage regulators \\
\hline
\end{tabular}

The two main drivers for DSSE in Hungary are:

- The necessity for capital expenditure (CAPEX) intensive network developments due to the increasing share of distributed generation (mainly photovoltaics (PV)) and the increasing amount of connection requests, and

- Growing power usage.

Therefore, any smart solution, e.g., active network components such as energy storage devices, voltage regulators, distributed generation control, and demand side management, is an alternative to conventional reinforcement methods. As the distribution system becomes more complex due to different active elements, observability is crucial for optimal control. DSSE can provide reliable input for grid operation software and can serve as the basis for further calculations (load flow and optimal dispatch calculations) in integrating flexibility, coordinated dispatch.

Another main value is the data that DSSE creates, as the power and voltage estimations are available for the analyzed grid. The necessary grid development calculations are usually conducted based on the static profile data and scarce measurements. Integration of the DSSE output enhances automatization of network calculations and increases modeling accuracy.

\section{Process-Oriented Review of DSSE}

Special characteristics of LV distribution networks are reflected in all segments of the SE process: network data, real, pseudo and virtual measurements, topology procession, observability analysis, and the SE algorithm itself. A vast amount of SE methods is published in the literature, including conventional voltage- or current-based static methods (weighted least squares, least mean squares, weighted least absolute value, least trimmed squares, etc.), use of artificial intelligence, and advanced techniques. A common approach in these studies is that they aim to decrease numerical errors and computational time of SE, usually benchmarking the improvement to the simple weighted least square (WLS) method. However, increasing the performance of SE methods beyond all seems to be unnecessary, since the perspective of typical DSSE applicability and the availability of measurement data have no such requirement. For this reason, the authors focus on those recent contributions in the literature, which have concentrated the LV DSSE, and present these studies in the field of measurements.

For achieving the aim to quantify and compare the impact of recent studies, the structure of the next sections follows the general build-up of SE algorithms. Section 3.1 discusses all the practical and theoretical criteria for fully observable network definition. Section 3.1.1 introduces the meter placement strategies both at the MV and the LV levels, using multivariate objective functions. Section 3.1.2 addresses the challenge of real time 
metering, data acquisition, and bad data detection. In most cases (especially at the LV level), the supplement of metered dataset via pseudo measurement is also an elemental part of DSSE methods. The third part (3.1.3) reviews these pseudo data generation methodologies for various load patterns. Section 3.2 focuses on network data and representative network models that are used for comparing performance of different SE algorithms. Finally, Section 3.3 presents the SE algorithms themselves.

\subsection{Observability Criteria}

\subsubsection{Classification of Meter Placement Techniques}

Besides the observability condition of SE execution, a wide variety of practical aspects must be considered for the placement of phasor measurement units (PMU). These aspects are quantified by objective functions for the reduction of investment costs [19], maximization of the estimation accuracy [20,21], physical implementation constraints [22], or a combination of these [23], all of which are relevant from a DSO perspective.

Meter placement optimization algorithms are mainly implemented as a linear [24], mixed [25], non-linear [26], or binary [27] integer programming problem, but examples for genetic [28,29] and greedy algorithms [30] are also found.

Performance evaluation is generally validated on a test case network (see Section 3.2) setting out the applicability limits of the results. Since test grids usually represent $\mathrm{MV} / \mathrm{HV}$ looped/meshed network topologies, the algorithms may result in suboptimal scenarios on radial LV grids. While test grids include fixed loads (constant grid state) dominantly, the proposed meter placement techniques often do not consider the need of pseudo data generation or the impact of bad or skewed data.

For a comparison, Table 2 shows the implementation objectives of six reviewed papers [31-36]. These validate the implemented PMU placement methods on IEEE 14 and IEEE $30 \mathrm{HV} / \mathrm{MV}$ bus systems, respectively. Despite the different optimization objectives, similar result patterns can be identified. In [32-36], an average of 10 PMUs were placed to 17 different buses with noticeable similarities on IEEE 30 bus system. Moreover, ref. [32-34] and [36] placed PMUs to the same four buses in case of an IEEE 14 network. These studies reflect approx. 20\% PMU penetration at least, which will be capital-intensive at the distribution level.

Table 2. Classification of possible DSSE utilization.

\begin{tabular}{ccc}
\hline Ref. & PMU Placement Objective & Optimization Algorithm \\
\hline$[31]$ & SE error minimization & particle swarm opt., artificial bee colony \\
\hline$[32]$ & minimize no. of PMUs & rational random walk \\
\hline$[33]$ & $\begin{array}{c}\text { minimize no. of critical measurements } \\
\text { and maximize redundancy }\end{array}$ & optimization using unreachability index \\
\hline$[34]$ & satisfy observability criteria & fruit fly optimization \\
\hline$[35]$ & minimize no. of PMUs & artificial bee colony \\
\hline$[36]$ & maximize redundancy & integer linear programming \\
\hline
\end{tabular}

\subsubsection{Bad Data Detection}

The accuracy of state estimation methodologies cannot be investigated individually, the evaluation performance highly depends on spatial and temporal data granularity as well as measurement accuracy. The observability criteria only represent the solvability of $\mathrm{SE}$, but do not guarantee any authenticity of the estimation results. For this reason, input data assessment is an essential step in transition to the physical implementation of SE. Ali and Exposito revealed that 1\% standard error of measurements may imply $10 \%$ standard error in SE [37]. The uncertainty of data measurement was evaluated in 76 papers of the reference list, the principally used solution was to define a constant uncertainty value [38], or modeling measurement error via a normal distribution function [39]. Beyond the few 
real implementations, it is a reasonable assumption due to the lack of real metering dataset. However, this issue highlights the weakness of simulation environments and the use of test bus grid topologies.

Furthermore, the practical modeling of measurement accuracy has various aspects. At the LV level, the literature dominantly proposes the application of (micro) phasor measurement units ( $\mu$ PMUs). These synchronous devices can capture waveform samples in every 10 milliseconds and reconstruct the phasor quantities using angle and magnitude measurement, while remote terminal units (RTUs) only provide information about the temporal change of phasor values in every 2 to $6 \mathrm{~s}$. Although PMU unit price had a significant decrease in the past decade, the major limiting factor of wide deployment is the investment cost of associated communication infrastructure (e.g., instrument transformers). Therefore, the parallel utilization of these technologies is an important step in transition to PMU-driven state estimation. Hybrid state estimation (HSE) enables the application of multiple input data granularity in two possible configurations: (i) one-phase HSE jointly process all the input data, and (ii) two-phase HSE manages RTU and PMU measurements in separate SE modules. Richter et al. proposed a mixed communication architecture and validated using HSE [40]. Beyond conceptual aspects, the technological challenges of using synchronized and non-synchronized measurements (e.g., communication delay, distortion of correction tables, digital-to-analog conversion, etc.) are discussed by Manousakis and Korres [41]. To eliminate temporal communication failures, Mosbah and El-Harawy introduced a dynamic estimation method using stochastic fractal search [42]. Saran and Miranda identified the erroneous metering data as a noise in the entire sample dataset [43]. The paper proposes a novel pre-filtering scheme of multiple autoencoders. Beyond temporary events and permanent meter device inaccuracies, outlier metering points are also widely discussed in the literature $[44,45]$. An alternative approach is introduced by Su et al. using circuit representation to estimate the non-observable part of the network and decreasing the number of necessary metering devices [46]. Othman et al. aimed to estimate active power losses in different configurations of radial low voltage networks [47].

\subsubsection{Pseudo Data Generation Techniques}

Despite the proliferation of smart metering technologies in energy industry, the LV distribution system operators usually have sparse spatial grid information due to the wide physical dimensions of the network. To fulfil observability criteria of the SE, pseudo measurement generation techniques are essential. However, the indicated increase in cumulative error of the metering points may question practical applicability of the DSSE results. The addressed problem results in various approaches to reduce pseudo data generation error to the scale of metering unit offset. The majority of the papers use historical load profiles and probability distributions for modeling the temporal change of node parameters [48,49]. Alternative predictor models use additional attributes (e.g., current state of the grid) or extract new features for better accuracy [50,51]. Pau et al. and Shafiei et al. addressed the spatial and temporal dependencies of pseudo data generation and the effect of meter placement strategies [52,53]. Teixeira et al. and Abdel-Majeed et al. introduced methodologies to compensate limitations (e.g., lack of power measurement, bad sampling frequency) of metering units. Due to the appearance of time-varying loads and expansion of distributed generation [54,55], Cheng et al. and Macii et al. focused on the influence of local prosumers on the accuracy of SE [56,57].

\subsection{Grid Models in DSSE, Practical Limitations of Model Topologies}

As the SE is to be performed on a specific network topology (or a set of topologies), it is important that all elements of the SE process should be tailored not only to the application supported by the SE but also to the characteristics of the tested network. The comparison of transmission and distribution networks is often discussed in the literature, but less emphasis is given to the differences of the MV and the LV distribution networks. Notable recent contributions in this field include the adequate handling of high $R / X$ 
ratios. Thukaram et al. [58] proposed and tested a robust three-phase SE for application in radial networks to handle this issue, while Abood et al. [59] used a regularized WLS SE to solve the problem of ill-conditioning, using an adjustable regularization parameter. The proper modeling of earthing and sequence components is discussed by Rankovic et al. [60], focusing on the modeling of distributed generators (DGs) with unbalanced output and by Liu et al. [61] who chose voltages as state variables of a WLS SE and pseudomeasurements of low-voltage systems to represent unbalances in the three-phase four conductor model. The analysis of symmetrical and asymmetrical network models is also discussed by many. Chusovitin et al. [62] compared a three-phase model to a decoupled model in which SE is solved for each phase. Chen et al. [63] used a three-phase DG model to represent unbalanced power injections, while Brinkmann et al. [64] developed a generic method that supports the decision between using the single- and three-phase state estimator method, depending on the network topology and metering configuration. Blazic [65] proposed the decoupling of the gain matrix to consider specific characteristics of low-voltage distribution network. SE was adapted to low currents by Svenda et al. [66] in accordance with back and forward sweep-based load flow calculations. Finally, the use of multi-area SE is demonstrated in [67] and [68], concluding that networks with large number of nodes can effectively be handled with such tools.

Literature on LV networks was also reviewed by authors, which was made difficult by misleading or incomplete descriptions at times. A total of 230 test cases were found for the DSSE, of which 223 included the description of the network model being used. A surprising finding was that $\sim 43 \%$ of the papers used HV networks (typically IEEE standard models). The remaining $57 \%$ was dominated by MV networks ( $48 \%$ of all cases), and only $9 \%$ of the reviewed test cases were performed at LV level, thus results of the vast majority of scientific studies were not validated for LV distribution networks.

The LV test cases included standard models (CGMES [69], CIGRÉ European LV [70], IEEE PES European LV [71]), real-world models from Germany [48,51,55,72], Australia [53], Portugal [54], the United Kingdom [59], and Slovenia [65,73]. The size of these networks shows large variations. Smaller ones have only 10-20 nodes, while the node count of wider areas exceeds 100. Cable and overhead networks are both found. No papers were identified in which standard models and real networks are both used, and most papers are also restricted to using a single network for demonstrating the DSSE.

\subsection{Application Constraints of the Algorithms}

As it was highlighted at the beginning of this section, the range of SE methods published in the literature is broad. Besides conventional solutions, large emphasis has been placed on the use of artificial intelligence: fuzzy logic [74,75], artificial neural network [76-79], particle swarm optimization [80,81], evolutionary algorithms [82], interior point optimization and brain storm optimization [83], biogeography based optimization [84], firefly algorithm [85], Kalman-filters [73,86-90] and advanced techniques (forecastaided SE [50,73], multi-area SE [14,63,67,68,91-93], and event triggered approaches [94]).

Although these complex methods outperform conventional voltage- or current-based static SE, they often rely on data that is not available with the desired spatial and temporal resolution.

Typical use cases of $\mathrm{LV}$ network operation are related to voltage or energy management issues, both of which are handled with temporal resolutions greater than a minute [72]. Most power quality performance indicators have to be evaluated using $10 \mathrm{~min}$ averages, according to EN 50160, while the typical electricity settlement period is $15 \mathrm{~min}$ long. Exceptions include, e.g., real time identification of power injection [95].

Tsitsimelis and Antón-Haró presented a regularized SE algorithm that operates on two timescales; observations from the SCADA are handled every $15 \mathrm{~min}$, while the PMU data are used to compute estimates between main time instants [96]. The method is presented to be robust against low redundancy measurement sets. A similar approach is used in [83] to create a framework for SE, using on-line and off-line computing, and 
measurement data of different temporal resolution. Combining low-resolution advanced metering infrastructure (AMI) data with other observations is also proposed by [40,97-99], which discusses the general data protection regulation (GDPR) aspects of using smart meter data for SE, concluding that voltage measurements from smart meters can be seen as non-private data.

Another often emerging drawback of complex SE methods is that the personnel of the system operator are rarely trained in the mathematical background of these methods, thus tuning, adapting, or developing an algorithm after installation is a challenging task [100]. If the personnel are undertrained, it limits the exploitation of the SE's potential and may lead to obsolescence.

Rasmussen et al. presented an interval estimation method, which combines worst-case loading scenarios based on fuse ratings and observations from smart meters, concluding that reliable estimations can be created in the case of low observability, if reliable network data is available [70].

Brandalik and Wellssow proposed the duplicated use of active and reactive power measurements, while maintaining linearity, thus improving the observability of LV networks [71].

Caro presented a robust search algorithm that aims to minimize the error of voltage angle estimation variability by selecting the proper bus for reference [101]. Adaptability of the results to a radial topology may be of interest [102].

\section{Evaluation of Pilot Projects}

The scope of this section is to analyze pilot applications and compare the approaches to theoretical research, underlining the limitations occurring from the technical circumstances, economic viability, and the need of the DSOs.

Several project disseminations can be found in the literature, where pilot applications and field test results are also available. A total of 27 different projects were assessed during this review, considering both MV and LV levels, focusing on Europe but also including projects from the United States of America and China. Table 3 summarizes the main attributes, as the project name and location, voltage level, main use case, main algorithm specifics, and data sources. In general, most pilot studies are connected to research projects in which consortiums (research institutes, technology providers, and DSOs) work together to arrive at practical results. The topology is usually limited, and certain lines (MV) or $\mathrm{MV} / \mathrm{LV}$ transformer areas (LV) are included in the pilot study. Major rollouts, with over 10,000 customers involved, at the LV level were conducted in Spain [103] and Poland [104]; other LV projects include only hundreds of customers.

The most common motivation for applying DSSE is renewable energy integration (as Table 3 describes), but the observability of networks in dense urban areas is also present [105]. Most of the pilots stressed the importance of observability; however, costbenefit analysis was not found in any of the studies, which shows the immaturity of the DSSE.

Regarding data sources at the MV level, HV/MV substation measurements are commonly available (therefore not included in Table 3). Besides, remote-controlled pole switches [106], PMUs [107], distributed generation and storage [108] and MV/LV substation [109] measurements are used, when available. In the case of LV DSSE, pilot studies clearly indicate the lack of observability [103], which becomes the most important aspect of algorithm developments. Smart meter data is another usual source of data [110]; however, the penetration of meters vary from $5 \%$ to $100 \%$ in different projects, which makes the actual pilot study results hard to compare. Phasor measurement and synchronized data are usually missing at the LV level (instrument development was performed to solve this, e.g., the GridEye sensor in [111] or "micro" PMUs [51,112]), which limits the possible applications.

Two separate approaches are identified considering algorithms: dominantly, WLS SE is used (with minor modifications, see Table 3), which highlights a dissonance between the 
algorithm development trends previously presented in Section 3 and the actual practical implementations. The structure of the distribution grid is usually radial and does not change over time, which can be exploited in simplifications, e.g., the reduction of nodes or the creation of virtual measurements by related power flows [113]. Advanced algorithms usually rely on data structures that cannot be constructed economically in practice; therefore, the simplest WLS solutions appear in the pilot projects. Conversely, the use of artificial intelligence (e.g., neural networks [114]) does not require accurate topology information and can be faster in computational time. However, the analysis of these models lacks long-term analysis (seasonal trends, effects of different day types such as weekdays, weekends, holidays), the advantages were only shown in limited datasets. The LV DSSE applications usually consider asymmetry and apply a three-phase and neutral model for the grid [115]. Most DSOs do not have a database for phase connections. This can be handled by measurements and examination of each area, but this requires a huge amount of human workforce in the case of a major roll-out. DSSE offers a possibility to create more accurate models for unbalanced operation and can help to identify phase connections based on measurements, instead of visual inspection $[9,27,44]$.

The most common limitation of DSSE is data quality [45]. Redundancy is hard to achieve at such a low level of instrumentation, and if the sufficient level is reached, loss of data (usually due to communication errors) leads to unavailability of the DSSE in the control center. Therefore, the pilot studies assess different ways to create adequate pseudo measurements based on:

- nominal values [51];

- $\quad$ synthetic load profiles [107];

- control functions (Volt/VAR compensators, on-line tap changing transformer setpoints, inverter control, etc.) [116];

- $\quad$ weather data [117].

Table 3. Summary of the main attributes from pilot applications.

\begin{tabular}{|c|c|c|c|c|}
\hline Project and Location & $\begin{array}{l}\text { Topology } \\
\text { Scope }\end{array}$ & Algorithm & Use Case & Metered Data Source \\
\hline $\begin{array}{c}\text { VENTEEA-France } \\
{[106,113]}\end{array}$ & MV & $\begin{array}{l}\text { WLS + Weighted } \\
\text { Least Absolute }\end{array}$ & $\begin{array}{l}\text { Closed-loop voltage control, } \\
\text { hosting capacity increase }\end{array}$ & $\begin{array}{l}\mathrm{U}, \mathrm{P}, \mathrm{Q} \text { sensors, } \mathrm{MV} / \mathrm{LV} \\
\text { transformer measurements, } \\
\text { remote-controlled } \\
\text { pole switches }\end{array}$ \\
\hline Monica-Spain [103] & $\mathrm{MV} / \mathrm{LV}$ & $\begin{array}{l}\text { N/A (asymmetry } \\
\text { consideration for LV) }\end{array}$ & $\begin{array}{l}\text { Observability, non-technical } \\
\text { loss identification }\end{array}$ & $\begin{array}{l}\text { Smart meters, } M V \text { voltage } \\
\text { sensors } L V \text { wide range of } \\
\text { sensors }(P, Q, U, I)\end{array}$ \\
\hline $\begin{array}{c}\text { Smart Area } \\
\text { Aachen-Germany } \\
{[51]}\end{array}$ & MV & $\begin{array}{l}\text { N/A (Monte carlo } \\
\text { error function) }\end{array}$ & $\begin{array}{c}\text { Renewable integration, } \\
\text { observability, situational } \\
\text { awareness }\end{array}$ & $\begin{array}{l}\mathrm{P}, \mathrm{Q}, \mathrm{I}, \mathrm{U} \text { sensors at } \mathrm{MV} / \mathrm{LV} \\
\text { transformers }\end{array}$ \\
\hline $\begin{array}{l}\text { UPGRID-Sweden } \\
\text { [118] }\end{array}$ & $\mathrm{MV} / \mathrm{LV}$ & $\mathrm{N} / \mathrm{A}$ & $\begin{array}{c}\text { Comparison and compatibility } \\
\text { between different suppliers, } \\
\text { network planning input, } \\
\text { observability }\end{array}$ & $\begin{array}{l}\text { RTU, fault indicators, } \\
\text { smart meter }\end{array}$ \\
\hline $\begin{array}{c}\text { evolvDSO-France } \\
{[114,119]}\end{array}$ & $\mathrm{MV} / \mathrm{LV}$ & $\begin{array}{c}\text { LV-Neural } \\
\text { network/(MV-OPF) }\end{array}$ & $\begin{array}{c}\text { Flexibility calculation (MV), } \\
\text { voltage monitoring (LV) }\end{array}$ & Smart meter, U sensors \\
\hline $\begin{array}{l}\text { PRICE GDI-Spain } \\
\text { [109] }\end{array}$ & MV & $\begin{array}{l}\text { Hachtel Augmented } \\
\text { Matrix Method }\end{array}$ & Hosting capacity increase & $\begin{array}{l}\text { Generation measurements, } \\
\text { Static compensators, RTU for } \\
\text { MV /LV transformers }\end{array}$ \\
\hline $\begin{array}{c}\text { Low carbon } \\
\text { London-Great Britain } \\
{[105]}\end{array}$ & MV & WLS & $\begin{array}{l}\text { Technical loss calculation, } \\
\text { meter placement calculation }\end{array}$ & $\begin{array}{l}\mathrm{MV} / \mathrm{LV} \text { transformer } \mathrm{U}, \mathrm{P} \\
\text { measurement }\end{array}$ \\
\hline
\end{tabular}


Table 3. Cont.

\begin{tabular}{|c|c|c|c|c|}
\hline Project and Location & $\begin{array}{l}\text { Topology } \\
\text { Scope }\end{array}$ & Algorithm & Use Case & Metered Data Source \\
\hline A2A-Italy [120] & MV & $\mathrm{N} / \mathrm{A}$ & $\begin{array}{l}\text { Fault localization, loss of } \\
\text { mains detection, local dispatch }\end{array}$ & $\begin{array}{l}\text { MV PMU, generation } \\
\text { measurements }\end{array}$ \\
\hline A.S.SE.M-Italy [121] & MV & $\mathrm{N} / \mathrm{A}$ & $\begin{array}{l}\text { Loss of mains detection, } \\
\text { voltage control }\end{array}$ & $\begin{array}{l}\text { MV PMU, generation } \\
\text { measurements }\end{array}$ \\
\hline $\begin{array}{c}\text { InteGRIDy-Italy } \\
{[117,122]}\end{array}$ & MV & $\mathrm{N} / \mathrm{A}$ & $\begin{array}{l}\text { Loss reduction, storage } \\
\text { operation enhancement, } \\
\text { hosting capacity increase }\end{array}$ & $\begin{array}{l}\text { Generation measurements, } \\
\text { smart meter }\end{array}$ \\
\hline France [123] & MV & $\begin{array}{l}\text { Heuristic power } \\
\text { adjustment }\end{array}$ & Algorithm development & PMU \\
\hline Denmark [107] & MV & WLS & $\begin{array}{c}\text { Minimal metering requirement } \\
\text { calculation, improving pseudo } \\
\text { measurements }\end{array}$ & PMU (end of the lines) \\
\hline $\begin{array}{l}\text { Sustainable-Portugal, } \\
\text { Greece [124] }\end{array}$ & MV & WLS & $\begin{array}{l}\text { DSSE evaluation, renewable } \\
\text { integration }\end{array}$ & Smart meters, PMU \\
\hline Korea, Canada [108] & MV & $\mathrm{N} / \mathrm{A}$ & $\begin{array}{c}\text { Event detection, voltage } \\
\text { observation }\end{array}$ & $\begin{array}{c}\text { Generation and energy } \\
\text { storage measurements, PMU }\end{array}$ \\
\hline Belgium [38] & MV & $\mathrm{N} / \mathrm{A}$ & PMU application verification & PMU \\
\hline $\begin{array}{c}\text { ADMS4LV-Portugal } \\
{[125]}\end{array}$ & LV & $\mathrm{N} / \mathrm{A}$ & Phase connection verification & Smart meter \\
\hline $\begin{array}{c}\text { Integrid-Portugal } \\
{[126]}\end{array}$ & LV & $\mathrm{N} / \mathrm{A}$ & $\begin{array}{c}\text { Flexibility market } \\
\text { enhancement }\end{array}$ & $\mathrm{N} / \mathrm{A}$ \\
\hline RESOLVD [127] & LV & $\mathrm{N} / \mathrm{A}$ & $\begin{array}{c}\text { Power quality, renewable } \\
\text { integration, flexibility } \\
\text { management }\end{array}$ & $\begin{array}{l}\text { PMU, smart meters, smart } \\
\text { assets (e.g., storage) }\end{array}$ \\
\hline Slovenia [73] & LV & $\begin{array}{l}\text { Extended Kalman } \\
\text { filter }\end{array}$ & $\begin{array}{l}\text { Algorithm test, EV charging } \\
\text { integration, voltage control }\end{array}$ & $\begin{array}{l}\text { U sensors, } \mathrm{P}-\mathrm{Q} \text { data for } \\
\text { nodes }\end{array}$ \\
\hline $\begin{array}{c}\text { SmartSCADA- } \\
\text { Germany } \\
{[45,110,115]}\end{array}$ & LV & $\begin{array}{l}\text { Linear algorithm } \\
\text { (from WLS) }\end{array}$ & Bad data detection & Smart meter \\
\hline $\begin{array}{c}\text { evolvDSO-Portugal } \\
{[114,128]} \\
\end{array}$ & LV & Neural network, & Observability & Smart meter, U sensors \\
\hline $\begin{array}{l}\text { LV SCADA-Portugal } \\
\text { [129] }\end{array}$ & LV & $\begin{array}{l}\text { Neural network, } \\
\text { particle swarm } \\
\text { optimization }\end{array}$ & Monitoring, observability & $\begin{array}{l}\text { Smart meter, LV RTU, } \\
\text { MV / LV On-line tap } \\
\text { changing transformers }\end{array}$ \\
\hline $\begin{array}{l}\text { UPGRID-Portugal } \\
\text { [130] }\end{array}$ & LV & $\mathrm{N} / \mathrm{A}$ & $\begin{array}{l}\text { Visualization for operators, } \\
\text { group error identification, } \\
\text { coordination between } \\
\text { operators and electricians }\end{array}$ & Smart voltage regulators \\
\hline $\begin{array}{l}\text { UPGRID-Poland } \\
\text { [104] }\end{array}$ & LV & $\mathrm{N} / \mathrm{A}$ & $\begin{array}{l}\text { Technical loss estimation, } \\
\text { event detection }\end{array}$ & $\begin{array}{l}\text { Fault indicators, Remote } \\
\text { controlled pole switched, } \\
\text { MV / LV transformer U, I } \\
\text { measurements }\end{array}$ \\
\hline Switzerland [111] & LV & WLS & $\begin{array}{l}\text { Asset management, grid } \\
\text { development input }\end{array}$ & $\begin{array}{c}\text { Smart meter, “Grid-eye" } \\
\text { sensors }(\mathrm{U}, \mathrm{I})\end{array}$ \\
\hline China [131] & MV & WLS-based & $\begin{array}{l}\text { Use of multi-source } \\
\text { measurements }\end{array}$ & Micro PMU, Smart meter \\
\hline USA [132] & MV & WLS-based & Voltage monitoring & MV sensors, Smart meters \\
\hline
\end{tabular}




\section{Conclusions and Outlook}

This paper addressed the practically applicable best practices and constraints of DSSE. As the DSOs face challenges in integrating further amounts of distributed generation and load, conventional grid planning, development, and operation methods become too expensive, and smart grid solutions can be competitive. The LV grids are currently practically unobservable, but the new elements and technical solutions offer data that can be used to create tailored solutions for a practically applicable DSSE.

Over 20 different use cases showed that the potential values are widely identified in consideration of the DSSE. However, there is a large gap between theoretical research and constraints deriving from the grid; most of the papers tried to integrate new sources of measurement and information to increase accuracy. The different applications were clustered into four main categories:

- Outage management and power quality;

- Data analysis;

- Renewable and e-mobility integration.

- Coordinated control.

It is witnessed that multiple meter placement objectives do not necessarily result in different placement patterns. The importance of bad or skewed data detection is usually neglected, giving suboptimal SE results. Especially in the case of LV grid topologies, pseudo data generation is essential to complement the real metering devices due to economic considerations. The comprehensive introduction of pseudo data generation techniques concluded that the performance highly depends on the grid structure and the penetration of the metering points.

Algorithm developments are usually tested in a network environment with a level of observability that is inconceivable in practice. The vast majority of the network models used are IEEE test systems, while LV grid analysis is rare. Therefore, an important direction for the near future may be the creation of a test system for LV, which covers the different circumstances of the regions around the world. This indicates that most of the developments should focus on the currently and potentially available data. Research is focused on the diversification of data sources (beside measurements from the grid and customers, the weather, historical energy values, and effect of local prosumers) in the pseudo measurement generation.

The analyzed pilot projects showed great potential in exploiting the values, including in the case of low level and bad data quality. The WLS method covers a definitive part of the pilot projects, while advanced computational methods such as neural networks are also present. Data sources are similar due to the current operation of DSOs: HV/MV substations, pole switches, and fault indicators on the MV network, smart meters, voltage (and oftentimes current) sensors, and smart assets on the LV network provide input for tailored DSSE solutions. However, real-time phasor measurements are not common; therefore, pseudo measurement inclusion is a regular attribute of DSSE. At the LV level, a usual time interval of $15 \mathrm{~min}$ is present, and asymmetry is a key factor, thus three-phase and neutral models are usually developed. The reliability test of pseudo measurements is the most common contribution of the papers since the observability issue is a key area for development.

In sum, DSSE seems to be a valuable tool in the LV SCADA expansion for DSOs, as active elements become increasingly common, thus increasing complexity and the number of possible system states. This paper contributes to the definition of fundamental principles for practical application, starting from the idea in which the DSSE can bring value, through the appropriate handling methods for the most important challenges (observation and data sources). The review shows examples for how to tailor an algorithm for the actual circumstances and gives insight into the international best practices from pilot projects. 
Author Contributions: Review of applications, I.V.; review of meter placement techniques, pseudo meauserements and bad data handling B.S.; review of algorithms B.H.; review of pilot projects I.T. All authors have read and agreed to the published version of the manuscript.

Funding: This research was supported by the Hungarian Academy of Sciences and E.ON Hungary through the "Célzott Lendület" Program application of the MTA-BME FASTER Research Group.

Conflicts of Interest: The authors declare no conflict of interest. The funders had no role in the design of the study; in the collection, analyses, or interpretation of data; in the writing of the manuscript; or in the decision to publish the results.

$\begin{array}{ll}\text { Abbreviations } \\ \text { The following abbreviations are used in this manuscript: } \\ \text { ADMS } & \text { Advanced distribution management system } \\ \text { CAPEX } & \text { Capital expenditure } \\ \text { DG } & \text { Distributed generator } \\ \text { DSSE } & \text { Distribution system state estimation } \\ \text { DSO } & \text { Distribution system operator } \\ \text { GDPR } & \text { General data protection regulation } \\ \text { GIS } & \text { Geographical information system } \\ \text { HSE } & \text { Hybrid State Estimation } \\ \text { HV } & \text { High voltage } \\ \text { LV } & \text { Low voltage } \\ \text { MV } & \text { Medium voltage } \\ \text { PMU } & \text { Phasor measurement unit } \\ \text { PV } & \text { Photovoltaic } \\ \text { RTU } & \text { Remote terminal unit } \\ \text { SCADA } & \text { Supervisory control and data acquisition } \\ \text { SE } & \text { State estimation } \\ \text { TSO } & \text { Transmission system operator } \\ \text { WLS } & \text { Weighted least square }\end{array}$

\section{References}

1. Primadianto, A.; Lu, C.-N. A Review on Distribution System State Estimation. IEEE Trans. Power Syst. 2016, 32, 3875-3883. [CrossRef]

2. Majdoub, M.; Boukherouaa, J.; Cheddadi, B.; Belfqih, A.; Sabri, O.; Haidi, T. A Review on Distribution System State Estimation Techniques. In Proceedings of the 2018 6th International Renewable and Sustainable Energy Conference (IRSEC), Rabat, Morocco, 5-8 December 2018; pp. 1-6.

3. Dehghanpour, K.; Wang, Z.; Wang, J.; Yuan, Y.; Bu, F. A survey on state estimation techniques and challenges in smart dis-tribution systems. IEEE Trans. Smart Grid 2019, 10, 2312-2322. [CrossRef]

4. Ahmad, F.; Rasool, A.; Ozsoy, E.; Sekar, R.; Sabanovic, A.; Elitaş, M. Distribution system state estimation-A step towards smart grid. Renew. Sustain. Energy Rev. 2018, 81, 2659-2671. [CrossRef]

5. López Gotti, I.; Lartategui Arteta, I.; Zubia Urrutia, H.; Sanz Heras, M.; González Ríos, J.; Sánchez Paniagua, A. Low voltage supervision system: Technology, applications, use cases and deployment. In Proceedings of the 25th International Conference on Electricity Distribution (CIRED, 2019), Madrid, Spain, 3-6 June 2019; pp. 1-5.

6. Duarte, D.; Kondo, D.; Matsuzaki, F.; Guaraldo, J.; Souza, M.; Silva, H.; Ferreira, M.; Silva, R.; Brito, L.; Ross, R.; et al. Identification and evaluation of energy theft using the state estimator in medium-voltage and low-voltage grids with exogenous parameters for planning expansion. CIRED-Open Access Proc. J. 2017, 2017, 2320-2324. [CrossRef]

7. Antoine, Q.; Uytterhoeven, S.; Pellichero, L. Applications of phasor measurement units in distribution grids—Practical return of experience. In Proceedings of the 25th International Conference on Electricity Distribution (CIRED, 2019), Madrid, Spain, 3-6 June 2019; pp. 1-5.

8. Mingotti, A.; Peretto, L. 1550-Online Monitoring Leads to Improve the Reliability and Sustainability of Power. In Proceedings of the 25th International Conference on Electricity Distribution 774613 (CIRED 2020), Berlin, Germany, $20-23$ September 2020.

9. Sampaio, G.; Janeiro, C.; Pereira, J.; Seca, L.; Viegas, P.; Silva, N.; Rodrigues, A. DER and load allocation for an unbalanced distribution networks state estimator. In Proceedings of the 23rd International Conference on Electricity Distribution (CIRED 2015), Lyon, France, 15-18 June 2015; pp. 1-5.

10. Jamali, S.; Bahmanyar, A. A new fault location method for distribution networks using sparse measurements. Int. J. Electr. Power Energy Syst. 2016, 81, 459-468. [CrossRef] 
11. Jamali, S.; Bahmanyar, A.; Bompard, E. Fault location method for distribution networks using smart meters. Meas. J. Int. Meas. Confed. 2017, 102, 150-157. [CrossRef]

12. Liu, L.; He, J.H. Application of weighted least square algorithm in distribution network state estimation with finite measurement information. In Proceedings of the 2014 International Conference on Power System Technology, Chengdu, China, 20-22 October 2014; pp. 134-138.

13. Margossian, H.; Sayed, M.A.; Fawaz, W.; Nakad, Z. Partial grid false data injection attacks against state estimation. Int. J. Electr. Power Energy Syst. 2019, 110, 623-629. [CrossRef]

14. Pau, M.; Ponci, F.; Monti, A.; Sulis, S.; Muscas, C.; Pegoraro, P.A. An Efficient and Accurate Solution for Distribution System State Estimation with Multiarea Architecture. IEEE Trans. Instrum. Meas. 2017, 66, 910-919. [CrossRef]

15. Xiang, Y.; Cobben, J.F.G. Improving operation of medium voltage grid with state estimator and advanced metering system. In Proceedings of the 2015 IEEE Eindhoven PowerTech, Eindhoven, The Netherlands, 29 June-2 July 2015; pp. 1-6. [CrossRef]

16. Melo, I.D.; Pereira, J.L.; Ribeiro, P.F.; Variz, A.M.; Oliveira, B.C. Harmonic state estimation for distribution systems based on optimization models considering daily load profiles. Electr. Power Syst. Res. 2019, 170, 303-316. [CrossRef]

17. Ye, G.; Nijhuis, M.; Cuk, V.; Cobben, J. Incorporating network uncertainties in voltage dip state estimation. Int. J. Electr. Power Energy Syst. 2019, 113, 888-896. [CrossRef]

18. Kubis, A.; Boller, M.; Kempler, J.; Uhlig, R.; Stiegler, M.; Stötzel, M. Enhancing operational awareness of distribution system operators with a semi-autonomous intelligent grid control suite. In Proceedings of the 25th International Conference on Electricity Distribution (CIRED 2019), Madrid, Spain, 3-6 June 2019; pp. 1-5.

19. Matsukawa, Y.; Watanabe, M.; Mitani, Y.; Othman, M.L. Multi-objective PMU placement optimization considering the placement cost including the current channel allocation and state estimation accuracy. Electr. Eng. Jpn. 2019, 207, 20-27. [CrossRef]

20. Raposo, A.A.M.; Rodrigues, A.; Silva, M. Optimal meter placement algorithm for state estimation in power distribution networks. Electr. Power Syst. Res. 2017, 147, 22-30. [CrossRef]

21. Xie, N.; Torelli, F.; Bompard, E.; Vaccaro, A. A graph theory based methodology for optimal PMUs placement and multiarea power system state estimation. Electr. Power Syst. Res. 2015, 119, 25-33. [CrossRef]

22. Zhao, Z.; Yu, H.; Li, P.; Kong, X.; Wu, J.; Wang, C. Optimal placement of PMUs and communication links for distributed state estimation in distribution networks. Appl. Energy 2019, 256, 113963. [CrossRef]

23. Kandenkavil, S.V.; Bhattacharya, K. Optimization Approaches to Distribution System State Estimation for Optimal Meter Placement. In Proceedings of the 2018 IEEE Electrical Power and Energy Conference (EPEC), Toronto, ON, Canada, 10-11 October 2018; pp. 1-6.

24. Attar, M.Z.; Namdari, F.; Aghaei, J.; Zohour, A.M. Optimal placement of phasor measurement units in the presence SCADA meters and considering the sensitivity constraints in Khouzestan province network. In Proceedings of the 2015 International Congress on Electric Industry Automation (ICEIA 2015), Shiraz, Iran, 24-25 February 2015; pp. 21-26. [CrossRef]

25. Chen, X.; Lin, J.; Wan, C.; Song, Y.; You, S.; Zong, Y.; Guo, W.; Li, Y. Optimal Meter Placement for Distribution Network State Estimation: A Circuit Representation Based MILP Approach. IEEE Trans. Power Syst. 2016, 31, 4357-4370. [CrossRef]

26. Almunif, A.; Fan, L. Optimal PMU placement for modeling power grid observability with mathematical programming methods. Int. Trans. Electr. Energy Syst. 2020, 30, 1-13. [CrossRef]

27. Moradi-Sepahvand, M.; Mashhour, E.; Mortazavi, S.S. Optimal placement of a combination of single-phase and three-phase $\mu$ PMUs for observability of smart distribution networks with asymmetrical structure. Int. J. Electr. Power Energy Syst. 2019, 105, 592-601. [CrossRef]

28. Shahriar, M.S.; Habiballah, I.O.; Hussein, H. Optimization of Phasor Measurement Unit (PMU) Placement in Supervisory Control and Data Acquisition (SCADA)-Based Power System for Better State-Estimation Performance. Energies 2018, 11, 570. [CrossRef]

29. Hubschneider, S.; Uhrig, M.; Suriyah, M.; Leibfried, T. Optimized meter placement in low voltage grids based on asymmetric state estimation. In Proceedings of the 2017 52nd International Universities Power Engineering Conference (UPEC), Heraklion, Greece, 29 August-1 September 2017; pp. 1-6.

30. Yao, Y.; Liu, X.; Li, Z. Robust Measurement Placement for Distribution System State Estimation. IEEE Trans. Sustain. Energy 2019, 10, 364-374. [CrossRef]

31. Al-Anbarri, K.A.; Hasan, M.F. Optimal placement of meters for power system state estimation by using artificial intellegence techniques, a comparative study. J. Eng. Sustain. Dev. 2018, 2018, 15-32. [CrossRef]

32. Parpaei, M.; Ghaffarzadeh, N.; Tayar, M.Z. Rational random walk-based optimal placement of phasor measurement units to enhance the initializing and guiding the optimization processes. Int. Trans. Electr. Energy Syst. 2017, 27, e2323. [CrossRef]

33. Álvarez, M.; Sellschopp-Sanchez, F.-S.; Vazquez, E. A PMUs placement methodology based on inverse of connectivity and critical measurements. Int. J. Electr. Power Energy Syst. 2015, 68, 336-344. [CrossRef]

34. Ramachandran, B.; Bellarmine, G.T. Improving observability using optimal placement of phasor measurement units. Int. J. Electr. Power Energy Syst. 2014, 56, 55-63. [CrossRef]

35. Shoaib Shahriar, M.; Ahmad, F.A.; Habiballah, I.O.; Asif, M.A.; Mukherjee, S. Artificial Bee Colony based Optimal PMU Placement in Power System State Estimation. In Proceedings of the 1st International Conference on. Advanced Information and. Communication Technology 2016 (ICAICT 2016), Chittagong, Bangladesh, 16-17 May 2016.

36. Xia, N.; Gooi, H.B.; Chen, S.; Wang, M. Redundancy based PMU placement in state estimation. Sustain. Energy Grids Netw. 2015, 2, 23-31. [CrossRef] 
37. Abur, A.; Expósito, A.G. Power System State Estimation: Theory and Implementation; Marcel Dekker, Inc.: New York, NY, USA, 2004.

38. Uytterhoeven, S.; Hoornaert, K.; Willems, D. Benefits of Phasor Measurement Units for Distribution Grid State Estimation: Practical Experience from an Urban Demonstrator. In Proceedings of the 23rd International Conference on Electricity Distribution (CIRED 2015), Lyon, France, 15-18 June 2015; pp. 15-18.

39. Ju, Y.; Sheng, W.; Song, X.; Wang, J.; Wu, W. Multi-phase distribution state estimation with only direct measurements. In Proceedings of the 2015 5th International Conference on Electric Utility Deregulation and Restructuring and Power Technologies (DRPT), Changsha, China, 26-29 November 2015; pp. 2690-2694.

40. Richter, M.; Komarnicki, P.; Hauer, I. Improving state estimation in smart distribution grid using synchrophasor technology: A comparison study. Arch. Electr. Eng. 2018, 67, 469-483.

41. Manousakis, N.M.; Korres, G.N. A hybrid power system state estimator using synchronized and unsynchronized sensors. Int. Trans. Electr. Energy Syst. 2018, 28, e2580. [CrossRef]

42. Mosbah, H.; El-Hawary, M. Optimization of neural network parameters by Stochastic Fractal Search for dynamic state estimation under communication failure. Electr. Power Syst. Res. 2017, 147, 288-301. [CrossRef]

43. Saran, M.A.; Miranda, V. State estimation pre-filtering with overlapping tiling of autoencoders. Electr. Power Syst. Res. 2018, 157, 261-271. [CrossRef]

44. Guo, Y.; Zhang, Y.; Srivastava, A.K. Data-Quality Aware State Estimation in Three-Phase Unbalanced Active Distribution System. In Proceedings of the 2018 IEEE Industry Applications Society Annual Meeting (IAS), Portland, OR, USA, 23-27 September 2018; pp. 1-7. [CrossRef]

45. Waeresch, D.; Brandalik, R.; Wellssow, W.; Jordan, J.; Bischler, R.; Schneider, N. Bad data processing for low voltage state estimation systems based on smart meter data. In Proceedings of the CIRED Workshop 2016, Helsinki, Finland, 14-15 June 2016; p. 47. [CrossRef]

46. Othman, M.M.; Ahmed, M.; Salama, M. A novel smart meter technique for voltage and current estimation in active distribution networks. Int. J. Electr. Power Energy Syst. 2018, 104, 301-310. [CrossRef]

47. Su, H.; Wang, C.; Liu, Z.; Wu, J.; Li, P. Novel voltage-to-power sensitivity estimation for phasor measurement unit-unobservable distribution networks based on network equivalent. Appl. Energy 2019, 250, 302-312. [CrossRef]

48. Cramer, M.; Goergens, P.; Potratz, F.; Schnettler, A.; Willing, S. Impact of three-phase pseudo-measurement generation from smart meter data on distribution grid state estimation. In Proceedings of the 23rd International Conference on Electricity Distribution (CIRED, 2015), Lyon, France, 15-18 June 2015; pp. 1-5.

49. Alves, J.; Pereira, J. Pseudo-Measurements Generation Using Energy Values from Smart Metering Devices. In Proceedings of the CIRED Workshop 2016, Helsinki, Finland, 14-15 June 2016; p. 140. [CrossRef]

50. Dobbe, R.; Arnold, D.; Liu, S.; Callaway, D.; Tomlin, C. Real-Time Distribution Grid State Estimation with Limited Sensors and Load Forecasting. In Proceedings of the 2016 ACM/IEEE 7th International Conference on Cyber-Physical Systems (ICCPS), Vienna, Austria, 11-14 April 2016; pp. 1-10.

51. Echternacht, D.; Franken, M.; Moser, A.; Geulen, U.; Zimmer, P.; Feilhauer, W.; Schrieder, W. Smart Area Aachen-In field test of meter placement and state estimation algorithms for distribution grids. In Proceedings of the 2015 IEEE PES Innovative Smart Grid Technologies Latin America (ISGT LATAM), Montevideo, Uruguay, 5-7 October 2015; pp. 435-439.

52. Pau, M.; Pegoraro, P.A.; Monti, A.; Muscas, C.; Ponci, F.; Sulis, S. Impact of Current and Power Measurements on Distribution System State Estimation Uncertainty. IEEE Trans. Instrum. Meas. 2018, 68, 3992-4002. [CrossRef]

53. Shafiei, M.; Nourbakhsh, G.; Arefi, A.; Ledwich, G.; Pezeshki, H. Single iteration conditional based DSSE considering spatial and temporal correlation. Int. J. Electr. Power Energy Syst. 2019, 107, 644-655. [CrossRef]

54. Teixeira, H.; Messias, A.A.; Pereira Barbeiro, P.N.; Lopes, D.A.; Pereira, J.; Matos, P.G. Using LV real-time data for pseudomeasurements generation in MV distribution networks. In Proceedings of the 23rd International Conference on Electricity Distribution (CIRED 2015), Lyon, France, 15-18 June 2015; pp. 1-5.

55. Abdel-Majeed, A.; Kattmann, C.; Tenbohlen, S.; Saur, R. Usage of Artificial Neural Networks for pseudo measurement modeling in low voltage distribution systems. In Proceedings of the 2014 IEEE PES General Meeting | Conference \& Exposition, National Harbor, MD, USA, 27-31 July 2014; pp. 1-5.

56. Cheng, G.; Song, S.; Lin, Y.; Huang, Q.; Lin, X.; Wang, F. Enhanced state estimation and bad data identification in active power distribution networks using photovoltaic power forecasting. Electr. Power Syst. Res. 2019, 177, 105974. [CrossRef]

57. Macii, D.; Barchi, G.; Moser, D. Impact of PMUs on state estimation accuracy in active distribution grids with large PV penetration. In Proceedings of the 2015 IEEE Workshop on Environmental, Energy, and Structural Monitoring Systems (EESMS) Proceedings, Trento, Italy, 9-10 July 2015; pp. 72-77.

58. Thukaram, D.; Jerome, J.; Surapong, C. A robust three-phase state estimation algorithm for distribution networks. Electr. Power Syst. Res. 2000, 55, 191-200. [CrossRef]

59. Abood, H.G.; Sreeram, V.; Mishra, Y. A new algorithm for improving the numerical stability of power system state estimation. IEEJ Trans. Electr. Electron. Eng. 2019, 14, 358-365. [CrossRef]

60. Ranković, A.; Maksimović, B.M.; Sarić, A.T. A three-phase state estimation in active distribution networks. Int. J. Electr. Power Energy Syst. 2014, 54, 154-162. [CrossRef]

61. Liu, Y.; Li, J.; Wu, L. State Estimation of Three-Phase Four-Conductor Distribution Systems with Real-Time Data from Selective Smart Meters. IEEE Trans. Power Syst. 2019, 34, 2632-2643. [CrossRef] 
62. Chusovitin, P.; Polyakov, I.; Pazderin, A. Three-phase state estimation model for distribution grids. In Proceedings of the 2016 IEEE International Conference on the Science of Electrical Engineering (ICSEE), Eilat, Israel, 16-18 November 2016; pp. 1-5.

63. Chen, S.; Wei, Z.; Sun, G.; Lu, N.; Sun, Y.; Zhu, Y. Multi-area distributed three-phase state estimation for unbalanced active distribution networks. J. Mod. Power Syst. Clean Energy 2016, 5, 767-776. [CrossRef]

64. Brinkmann, B.; Bicevskis, K.; Scott, R.; Negnevitsky, M. Evaluation of single-and three-phase state estimation in distribution networks. In Proceedings of the 2017 Australasian Universities Power Engineering Conference (AUPEC), Melbourne, VIC, Australia, 19-22 November 2017; pp. 1-5.

65. Blazic, B.; Antoncic, M. LV Network State Estimation Using Decoupled Load-flow Algorithm. In Proceedings of the CIRED Workshop (CIRED: 2018), Ljubljana, Slovenia, 7-8 June 2018; pp. 7-8.

66. Švenda, G.; Strezoski, V.; Kanjuh, S. Real-life distribution state estimation integrated in the distribution management system. Int. Trans. Electr. Energy Syst. 2017, 27, e2296. [CrossRef]

67. Zhou, X.; Liu, Z.; Guo, Y.; Zhao, C.; Huang, J.; Chen, L. Gradient-Based Multi-Area Distribution System State Estimation. IEEE Trans. Smart Grid 2020, 11, 5325-5338. [CrossRef]

68. Eghbali, O.; Kazemzadeh, R.; Amiri, K. Multi-Area State Estimation Based on PMU Measurements in Distribution Networks. J. Oper. Autom. Power Eng. 2019, 8, 1. [CrossRef]

69. Binot, F.; Le, T.; Petit, M. A three-phase four-wire state estimator algorithm for low voltage networks management. In Proceedings of the 25th International Conference on Electricity Distribution (CIRED 2019), Madrid, Spain, 3-6 June 2019; pp. 1-5.

70. Rasmussen, T.B.; Yang, G.; Nielsen, A.H. Interval estimation of voltage magnitude in radial distribution feeder with minimal data acquisition requirements. Int. J. Electr. Power Energy Syst. 2019, 113, 281-287. [CrossRef]

71. Brandalik, R.; Wellssow, W.-H. Power system state estimation with extended power formulations. Int. J. Electr. Power Energy Syst. 2020, 115, 105443. [CrossRef]

72. Abdel-Majeed, A.; Tenbohlen, S.; Rudion, K. Effects of state estimation accuracy on the voltage control of low voltage grids. In Proceedings of the 2015 International Symposium on Smart Electric Distribution Systems and Technologies (EDST), Vienna, Austria, 8-11 September 2015; pp. 526-530.

73. Antončič, M.; Papič, I.; Blažič, B. Robust and Fast State Estimation for Poorly-Observable Low Voltage Distribution Networks Based on the Kalman Filter Algorithm. Energies 2019, 12, 4457. [CrossRef]

74. Prasad, S.; Kumar, D.V. Hybrid fuzzy charged system search algorithm based state estimation in distribution networks. Eng. Sci. Technol. Int. J. 2017, 20, 922-933. [CrossRef]

75. Pavão, R.K.; Homma, R.Z.; dos Santos, T.T.; Chumbinho, R.; Lemos FA, B.; Khairalla, I.K. Fuzzy state estimation applied to smart distribution network automation functions. In Proceedings of the 23rd International Conference on Electricity Distribution (CIRED 2015), Lyon, France, 15-18 June 2015; pp. 1-5.

76. Ahmad, F.; Tariq, M.; Farooq, A. A novel ANN-based distribution network state estimator. Int. J. Electr. Power Energy Syst. 2019, 107, 200-212. [CrossRef]

77. Zhang, L.; Wang, G.; Giannakis, G.B. Real-Time Power System State Estimation and Forecasting via Deep Unrolled Neural Networks. IEEE Trans. Signal Process. 2019, 67, 4069-4077. [CrossRef]

78. Menke, J.-H.; Bornhorst, N.; Braun, M. Distribution system monitoring for smart power grids with distributed generation using artificial neural networks. Int. J. Electr. Power Energy Syst. 2019, 113, 472-480. [CrossRef]

79. Mestav, K.R.; Luengo-Rozas, J.; Tong, L. State Estimation for Unobservable Distribution Systems via Deep Neural Networks. In Proceedings of the 2018 IEEE Power \& Energy Society General Meeting (PESGM), Portland, OR, USA, 5-10 August 2018; pp. 1-5.

80. Tungadio, D.H.-S.; Jordaan, J.A.; Siti, M.W. Power system state estimation solution using modified models of PSO algorithm: Comparative study. Meas. J. Int. Meas. Confed. 2016, 92, 508-523. [CrossRef]

81. Iwata, S.; Fukuyama, Y. Differential evolutionary particle swarm optimization for load adjustment distribution state estimation using correntropy. Electr. Eng. Jpn. 2018, 205, 11-21. [CrossRef]

82. Basetti, V.; Chandel, A.K.; Chandel, R. Power system dynamic state estimation using prediction based evolutionary technique. Energy 2016, 107, 29-47. [CrossRef]

83. Azuma, D.; Fukuyama, Y.; Jintsugawa, T.; Fujimoto, H.; Matsui, T. Improved Brain Storm Optimization with Differential Evolution strategies for Load Adjustment Distribution State Estimation Using Correntropy. IFAC-PapersOnLine 2019, 52, 449-454. [CrossRef]

84. Kalpanadevi, M.; Neela, R. BBO Algorithm for Line Flow Based WLS State Estimation. Mater. Today Proc. 2018, 5, 318-328. [CrossRef]

85. Khorshidi, R.; Shabaninia, F.; Niknam, T. A new smart approach for state estimation of distribution grids considering renewable energy sources. Energy 2016, 94, 29-37. [CrossRef]

86. Lu, Z.; Wei, Z.; Sun, Y. Power system dynamic state estimation considering correlation of measurement error from PMU and SCADA. Concurr. Comput. Pr. Exp. 2019, 31, e4726. [CrossRef]

87. Huang, S.-C.; Lu, C.-N.; Lo, Y.-L. Evaluation of AMI and SCADA Data Synergy for Distribution Feeder Modeling. IEEE Trans. Smart Grid 2015, 6, 1639-1647. [CrossRef]

88. Brüggemann, A.; Görner, K.; Rehtanz, C. Evaluation of extended Kalman filter and particle filter approaches for quasi-dynamic distribution system state estimation. CIRED-Open Access Proc. J. 2017, 2017, 1755-1758. [CrossRef]

89. Ćetenović, D.N.; Ranković, A.M. Optimal parameterization of Kalman filter based three-phase dynamic state estimator for active distribution networks. Int. J. Electr. Power Energy Syst. 2018, 101, 472-481. [CrossRef] 
90. Goleijani, S.; Ameli, M.T. Neural network-based power system dynamic state estimation using hybrid data from SCADA and phasor measurement units. Int. Trans. Electr. Energy Syst. 2018, 28, e2481. [CrossRef]

91. Chen, Y.; Kong, X.; Yong, C.; Ma, X.; Yu, L. Distributed State Estimation for Distribution Network with Phasor Measurement Units Information. Energy Procedia 2019, 158, 4129-4134. [CrossRef]

92. Dzafic, I.; Huseinagic, I. Real Time Distribution System State Estimation Based on Interior Point Method. Southeast Eur. J. Soft Comput. 2014, 3, 32-38. [CrossRef]

93. Korres, G.N. A Distributed Multiarea State Estimation. IEEE Trans. Power Syst. 2011, 26, 73-84. [CrossRef]

94. Francy, R.C.; Farid, A.M.; Youcef-Toumi, K. Event triggered state estimation techniques for power systems with integrated variable energy resources. ISA Trans. 2015, 56, 165-172. [CrossRef]

95. Issicaba, D.; Costa, A.S.; Colombo, J.L. Real-Time Monitoring of Points of Common Coupling in Distribution Systems Through State Estimation and Geometric Tests. IEEE Trans. Smart Grid 2015, 7, 9-18. [CrossRef]

96. Tsitsimelis, A.; Antón-Haro, C. A regularized state estimation scheme for a robust monitoring of the distribution grid. Int. J. Electr. Power Energy Syst. 2020, 117, 105621. [CrossRef]

97. Huang, M.; Wei, Z.; Sun, G.; Zang, H. Hybrid State Estimation for Distribution Systems with AMI and SCADA Measurements. IEEE Access 2019, 7, 120350-120359. [CrossRef]

98. Liu, M. State estimation in a smart distribution system. HKIE Trans. 2017, 24, 1-8. [CrossRef]

99. Weisenstein, M.; Wellssow, W.H.; Brandalik, R. Investigation and comparison of different methods for lv grid state estimation considering privacy issues. In Proceedings of the 25th International Conference on Electricity Distribution (CIRED, 2019), Madrid, Spain, 3-6 June 2019; pp. 1-5.

100. Xygkis, T.C.; Manousakis, N.; Korres, G.; Hatziargyriou, N. Distribution Grid State Estimation Using Load Pseudomeasurements and Topology Identification Techniques. In Proceedings of the 23rd International Conference on Electricity Distribution (CIRED, 2015), Lyon, France, 15-18 June 2015; pp. 1-5.

101. Caro, E. Uncertainty analysis of power system state estimates and reference bus selection. Electr. Power Syst. Res. 2016, 136, 322-330. [CrossRef]

102. Yu, L.; Kong, X.; Chen, Y. Internal state estimation for distribution network with PMU measurement information. In Proceedings of the 2019 IEEE Innovative Smart Grid Technologies-Asia (ISGT Asia), Chengdu, China, 21-24 May 2019; pp. 1149-1153.

103. Almeida, B.; Santos, R.J. MONICA-Advanced monitoring and control in MV and LV distribution networks. In Proceedings of the 25th International Conference on Electricity Distribution (CIRED 2019), Madrid, Spain, 3-6 June 2019; pp. 1-5.

104. Noske, S.; Falkowski, D.; Swat, K.; Boboli, T. UPGRID project: The management and control of LV network. CIRED-Open Access Proc. J. 2017, 2017, 1520-1522. [CrossRef]

105. Dragovic, J.; Djapic, P.; Bilton, M.J.; Pudjianto, D.; Strbac, G. Application of Distribution System State Estimation on Engineering Instrumentation Zones of Low Carbon London. In Proceedings of the 23rd International Conference on Electricity Distribution (CIRED 2015), Lyon, France, 15-18 June 2015; pp. 1-5.

106. Croteau, D.; Carre, O. Distribution state estimation: Outcomes from a field implementation aimed at tackling MV mastering in the presence of distributed energy resources (DER). CIRED-Open Access Proc. J. 2017, 2017, 1715-1717. [CrossRef]

107. Pokhrel, B.R.; Bak-Jensen, B.; Pillai, J.R. Integrated Approach for Network Observability and State Estimation in Active Distribution Grid. Energies 2019, 12, 2230. [CrossRef]

108. Chu, C.; Kim, J. Development and field test result of KEPCO distribution management system. In Proceedings of the CIRED Workshop 2018 (CIRED 2018), Ljubljana, Slovenia, 7-8 June 2018; pp. 1-5.

109. González, R.; Bocos, M.; Romero, J.; Díaz ME, I.; Gastalver, A. State estimation in MV distribution networks: Experience in the Spanish smart grid project PRICE-GDI. In Proceedings of the CIGRÉ 2016, Paris, France, 21-26 August 2016.

110. Waeresch, D.; Brandalik, R.; Wellssow, W.H.; Jordan, J.; Bischler, R.; Schneider, N. Linear state estimation in low voltage grids based on smart meter data. In Proceedings of the 2015 IEEE Eindhoven PowerTech, Eindhoven, Netherlands, 29 June-2 July 2015 ; pp. 1-6.

111. Eggenschwiler, L.; Nauts, O.; Favre-perrod, P.; Rampazzo, J.; Mousavi, A.O. Performance evaluation of distribution system state estimator using different measurement devices. In Proceedings of the 25th International Conference on Electricity Distribution (CIRED, 2019), Madrid, Spain, 3-6 June 2019; pp. 1-5.

112. Silva, N.; Silva, P.M.; Pereira, J.; Seca, L.; Melo, F.; Madureira, A. LV SCADA-How to effectively manage LV networks with limited topology and electrical characteristics data. In Proceedings of the 23rd International Conference on Electricity Distribution (CIRED 2015), Lyon, France, 15-18 June 2015; pp. 1-5.

113. Kamga, K.; Carre, O. Voltage management in the presence of distributed energy resources-Field implementation of a robust distribution state estimator with errors in sensor data. In Proceedings of the 25th International Conference on Electricity Distribution (CIRED, 2019), Madrid, Spain, 3-6 June 2019; pp. 1-4.

114. Teixeira, H.; Barbeiro, P.P.; Pereira, J.; Bessa, R.; Matos, P.; Lemos, D.; Morais, A.; Caujolle, M.; Sebastian-Viana, M. A State Estimator for LV Networks: Results from the EvolvDSO Project. In Proceedings of the CIRED Workshop 2016, Helsinki, Finland, 14-15 June 2016; p. 136. [CrossRef]

115. Waeresch, D.; Brandalik, R.; Wellssow, W.H.; Jordan, J.; Bischler, R.; Schneider, N. Field test of a linear three-phase low-voltage state estimation system based on smart meter data. CIRED-Open Access Proc. J. 2017, 2017, 1773-1776. [CrossRef] 
116. Biener, W.; Killinger, S.; Wille-Haussmann, B.; Wittwer, C. Modelling active and reactive power of PV-systems as input for State Estimation. In Proceedings of the 4th Solar Integration Workshop: International Workshop on Integration of Solar Power into Power, Berlin, Germany, 10-11 November 2014.

117. Falabretti, D.; Delfanti, M.; Merlo, M. Distribution networks' observability: A novel approach and its experimental test. Sustain Energy, Grids Netw. 2018, 13, 56-65. [CrossRef]

118. Etherden, N.; Johansson, A.K.; Ysberg, U.; Kvamme, K.; Pampliega, D.; Dryden, C. Enhanced LV supervision by combining data from meters, secondary substation measurements and medium voltage supervisory control and data acquisition. CIRED-Open Access Proc. J. 2017, 2017, 1089-1093. [CrossRef]

119. Sebastian, M.V.; Caujolle, M.; Maraver, B.G.; Pereira, J.; Sumaili, J.; Barbeiro, P.; Silva, J.; Bessa, R. LV state estimation and TSO-DSO cooperation tools: Results of the French field tests in the evolvDSO project. CIRED-Open Access Proc. J. 2017, 2017, 1883-1887. [CrossRef]

120. Delfanti, M.; Fasciolo, E.; Olivieri, V.; Pozzi, M. A2A project: A practical implementation of smart grids in the urban area of Milan. Electr. Power Syst. Res. 2015, 120, 2-19. [CrossRef]

121. Delfanti, M.; Falabretti, D.; Fiori, M.; Merlo, M. Smart Grid on field application in the Italian framework: The A.S.SE.M. project. Electr. Power Syst. Res. 2015, 120, 56-69. [CrossRef]

122. Falabretti, D.; Moncecchi, M.; Mirbagheri, M.; Bovera, F.; Fiori, M.; Merlo, M.; Delfanti, M. San Severino Marche Smart Grid Pilot within the InteGRIDy project. Energy Procedia 2018, 155, 431-442. [CrossRef]

123. Menke, J.-H.; Hegemann, J.; Gehler, S.; Braun, M. Heuristic monitoring method for sparsely measured distribution grids. Int. J. Electr. Power Energy Syst. 2018, 95, 146-155. [CrossRef]

124. Pereira, J.; Barbeiro, P.P.; Teixeira, H.; Korres, G.; Themistoklis, X.; Nikolaos, M.; Koukoula, D.; Moutis, P. Advanced Local Distribution Grid Monitoring/State-Estimation. Delivarable 3.3. of the Project Sustainable. 2012. Available online: https: // repositorio-aberto.up.pt/bitstream/10216/83284/2/44855.pdf (accessed on 18 August 2021).

125. Kotsalos, K.; Simoes, A.; Marques, L.; Campos, F.; Sampaio, G.; Gouveia, C.; Pereira, J.; Seca, L.; Teixeira, H. (ADMS4LV)Improved observability of LV grids based on advanced analytics. In Proceedings of the 25th International Conference on Electricity Distribution (CIRED 2019), Madrid, Spain, 3-6 June 2019; pp. 1-5.

126. Costa, J.; Rua, D.; Moreira, J.; Fonseca, D.; Trocato, C.; Madureira, A. LV network control architecture: H2020 INTEGRID case study. In Proceedings of the CIRED Workshop 2018 (CIRED 2018), Ljubljana, Slovenia, 7-8 June 2018; pp. 1-4.

127. Frigola, J.M.; Tuiskula, H.; Gallart, R. Resolvd-Renewable Penetration Levered by Efficient Low Voltage Distribution Grids Specifcations and Use Case Analysis. In Proceedings of the 25th International Conference \& Exhibition on Electricity Distribution, Madrid, Spain, 3-6 June 2019; pp. 1-5.

128. Fonseca, N.; Silva, J.P.; Silva, A.; Sumaili, J.; Seca, L.; Bessa, R.; Pereira, J.; Matos, M.; Matos, P.; Morais, A.; et al. EvolvDSO grid management tools to support TSO-DSO cooperation. In Proceedings of the CIRED Workshop 2016, Helsinki, Finland, 14-15 June 2016; p. 72. [CrossRef]

129. Barbeiro, P.; Pereira, J.; Teixeira, H.; Seca, L.; Silva, P.; Silva, N.; Melo, F. LV SCADA Project: In-Field Validation of a Distribution State Estimation Tool for LV Networks. In Proceedings of the CIRED Workshop 2016, Helsinki, Finland, 14-15 June 2016; p. 134. [CrossRef]

130. Pires, R.; Louro, M.; Calado, H.; Nunes, P.; Almeida, B. Improved supervision and control of the lv portuguese network. In Proceedings of the 25th International Conference on Electricity Distribution (CIRED, 2019), Madrid, Spain, 3-6 June 2019; pp. 1-5.

131. He, X.; Li, C.; Du, M.; Dong, H.; Li, P. Hybrid Measurements Based Fast State Estimation for Power Distribution System. IEEE Access 2021, 9, 21122-21129.

132. Schoene, J.; Humayun, M. The Challenges of Distribution System State Estimation. IEEE Smart Grid Community Webinars. 2021. Available online: https:/ / smartgrid.ieee.org/resources/webinars/distribution/case-study-the-challenges-of-distributionsystem-state-estimation (accessed on 18 August 2021). 